\title{
I fear COVID but diabetic foot (DF) is worse: a survey on patients' perception of a telemedicine service for DF during lockdown
}

\author{
Elisabetta lacopi ${ }^{1}$ (1) $\cdot$ L. Pieruzzi $^{1} \cdot$ C. Goretti ${ }^{1} \cdot$ A. Piaggesi ${ }^{1}$
}

Received: 25 October 2020 / Accepted: 1 December 2020 / Published online: 13 January 2021

(c) Springer-Verlag Italia S.r.l., part of Springer Nature 2021

\begin{abstract}
Aims To evaluate the patients' perceptions of telemedicine visits during COVID-19 lockdown and their level of anxiety about COVID and diabetic foot (DF).

Methods In May 2020, we contacted by phone all the patients who underwent in March and April to remote monitoring visits for DF during the lockdown for COVID-19, with a structured interview, focusing on their perceptions about telemedicine service for DF and on the anxiety toward COVID and DF.

Results We analyzed 257 remote monitoring visits in 211 patients. Two hundred and six patients answered the follow-up interview; 177 patients $(85.9 \%)$ remembered the monitoring visit, $140(67.9 \%)$ the health care professional and 181 patients $(87.9 \%)$ the reason of contact; 169 patients were alone during the visit, 37 with a relative. Patients judged useful both the monitoring during pandemic $(4.35 \pm 0.28$ on a maximum of five $)$ and the possibility to continue after the lockdown ( $4.34 \pm 0.23$ on a maximum of five). Eventually, we observed that DF patients were more worried by DF than by COVID on a scale from 0 (not fear at all) to 5 (terrified) $(4.79 \pm 0.05$ vs. $3.27 \pm 1.03, p<0.05)$. This difference was higher in previously ulcerated patients $(4.84 \pm 0.03$ vs. $3.03 \pm 1.13, p<0.05)$ and even more in amputees $(4.93 \pm 0.03$ vs. $2.73 \pm 1.21, p<0.05)$. Conclusions DF patients appreciated televisits during lockdown and the continuation of this service after its end. In this context DF prevails on COVID in the worries of patients, especially if they are recurrent ones.
\end{abstract}

Keywords Diabetic foot $\cdot$ COVID $\cdot$ Follow-up $\cdot$ Pandemic

\section{Introduction}

At the end of 2019, China Government reported a cluster of cases of pneumonia in people associated with the Huanan Seafood Wholesale Market in Wuhan, Hubei Province [1]. On January 7, 2020, Chinese health authorities confirmed that these cases were due to a novel coronavirus, called 2019-nCoV [2], able to a person-to-person transmission [3]. In the following weeks slightly less than 10 similar cases had been reported in 21 countries [4]. From many sources arrived at World Governments the call to reduce

This article belongs to the topical collection Health Education and Psycho-Social Aspects, managed by Massimo Porta and Marina Trento.

Elisabetta Iacopi

elisabettaiacopi@gmail.com

1 Diabetic Foot Section, Pisa University Hospital, Via Paradisa 2, 56126 Pisa, PI, Italy interpersonal contacts both in everyday life and in healthcare [5, 6]. In chronic and frail patients, this would mean to reduce as much as possible their access to hospitals, considered places a high risk for contagion [7]. Furthermore, all not emergent medical conditions and all deferrable evaluations had to be thus postponed in preserving all available resources for pandemic effort, since reduction or cancellation of routine services can mobilize resources and staff to cope with the emergency due to pandemic [8].

On March 10th, 2020, Italian Government declared the emergency status and the lockdown of all activities to reduce the spread of transmission of SARS-COV2 virus, responsible of the syndrome known as COVID-19 [9].

Since the early beginning it had been clearly showed by first epidemiological analysis how age and preexisting comorbidities represented negative predictive factors associated with a bad outcomes in patients affected by COVID infection [10]. Already a forerunner meta-analysis, performed in China on more than 1500 patients, recognized the three more prevalent comorbidities affecting COVID-19 
patients in hypertension, cardio-cerebrovascular disease and diabetes. Furthermore, diabetes and hypertension determine a twofold increase in the risk of need for Intensive care unit [11].

Diabetic Foot (DF) represents the main cause of hospital admission and of face-to-face visits, both in election and in emergent conditions. Such patients are usually affected by multiple comorbidities and therefore even more frail. Moreover, the causative pathologies are subtle so that the local state can abruptly precipitate also in patients regularly followed and adhering to given indications [12].

The unavoidable delay or cancellation of many face-toface visits and clinical services created a potential danger in patients with active ulceration, ischemia or other DF-related conditions, such as Charcot disease, that needed frequent clinical evaluation. This delay had also stopped any primary or secondary prevention activity, thus reducing our effectiveness in preventing ulcerations. Fear for COVID had actually convinced many patients with new acute disease to delay their access in hospital, increasing the severity of the clinical status and limiting our possibilities in limb salvage [13].

During lockdown period, our DF clinic had to strictly select patients and reserve face-to-face visits to those with critical limb ischemia or acute infection who required urgent surgical procedures. For all the other patients there was the need to rethink a way to remain in contact, not exposing the patients to COVID risk.

In such a context, Tuscany Health Authorities gave to Diabetologist and Diabetic foot care specialist the possibility to manage chronic patients through a dedicated system of telemedicine, supplying both software and hardware for a program of telemedicine, that we used to maintain a contact with our patients in need of close monitoring [14, 15].

\section{Aim of the study}

Aims of our study were to evaluate the patients' perception of the telemedicine experience during lockdown, and to esteem their level of anxiety towards DF and COVID, respectively.

\section{Patients and methods}

In the last week of May 2020, all patients who had undergone to televisits during lockdown (March and April) were contacted again by phone by the same investigator (E.I.) and submitted to a questionnaire, as reported in Table 1 . The questionnaire focused the remote monitoring interaction occurred during lockdown through questions inquiring if patients remembered the call, the topic of the call and the person who talked to, or if they were alone during the call. We evaluated also if patients who remember the monitoring visit and its characteristics eventually differed for demographic and clinical parameters from those who did not remember. We asked furthermore to give a score, ranging from 1 , meaning not at all, to 5, meaning completely yes, to their opinion on the possibility to continue televisits also after the end of pandemic period.

The questionnaire investigated moreover, once again through the same pattern, about patient's anxiety about diabetic foot and COVID infection.

As per standard protocol of our hospital, patients during the monitoring had provided formal oral consent to the introduction of their data in a database and to their non-nominal use in an aggregate form.

Table 1 Phone interview administered to patients

\begin{tabular}{lc}
\hline Question & Answer \\
\hline $\begin{array}{l}\text { Do you remember that you have been contacted by phone by DF clinic in last weeks? } \\
\text { Do you remember the name of the person you spoke to? }\end{array}$ & $\begin{array}{c}\text { Yes/No } \\
\text { Yes/No } \\
\text { Do you remember why you were contacted? }\end{array}$ \\
$\begin{array}{l}\text { The conversation only took place between you and the doctors or someone else took part } \\
\text { Who else participated in the phone call? }\end{array}$ & Yes/No \\
& Relative/Car- \\
egiver/ Nurse/ & Doctor \\
Assign a score from 1 (not at all) to 5 (completely yes) to the following issues & $1-5$ \\
Have you found the contact useful regarding your health condition? & $1-5$ \\
Have you been given useful information for the management of your pathology? & $1-5$ \\
$\begin{array}{l}\text { Do you think that this way of interacting between you and the doctors should be continued even after the end of the emer- } \\
\text { gency? }\end{array}$ & $1-5$ \\
As far as your health is concerned, how much diabetic foot worries you? & $1-5$ \\
Regarding your state of health, how concerned you are about being infected with COVID-19? &
\end{tabular}




\section{Statistical analysis}

Quantitative variables are expressed as mean and standard deviation, while qualitative variables as frequencies and percentages. Data were compared with Chi-square and Fisher's exact test for the categorical data and with Student $t$ test for the continuous variables. The statistical analysis was performed with the SAS software (SAS Institute, Cary, $\mathrm{NC)}$. A $p$ value of less than 0.05 was considered statistically significant.

\section{Results}

We performed 257 remote monitoring visits in 211 different patients (1.22 visit/patient). The cohort was mainly composed by male patients $(64.9 \%)$ and had a mean age of $73 \pm 11$ years.

Two hundred and six patients (97.6\%) accepted to be interviewed. The characteristics of these patients are reported in Table 2; they were still predominantly male $(64.6 \%)$, and had a mean age of $72 \pm 10$ years. They were affected by diabetes, with a mean duration of $18 \pm 6$ years and had had their first diabetic foot episode $12 \pm 8$ years ago. Among the patients who underwent interview, 74 (35.9\%) had an active chronic ulcer, $98(47.6 \%)$ were followed in secondary prevention and $34(16.5 \%)$ were in primary prevention.

\section{Characteristics of phone interviews}

The first part of the interview investigated what patients remembered of the remote monitoring interaction: as reported in Fig. 1, 177 patients (85.9\%) remembered the remote monitoring visit during the lockdown, 140 (67.9\%) were able to mention whom they talked to and 181 patients (87.9\%) reminded the reason why they had been contacted.

Regarding the differences between patients who remember the monitoring visit and those who did not remember. We found that patients who did not remember the remote monitoring and its reason were significantly more frequently male $(72.4 \%$ vs. $61.6 \% p<0.01$ and $68.0 \%$ vs. $61.2 \%$ $p<0.01)$ and older $(73 \pm 11$ vs. $68 \pm 13 p<0.01$ and $77 \pm 10$ vs. $71 \pm 12 p<0.01)$. No difference between patients who remembered the name of the person they interacted with and those who did not remember. Analyzing instead patients with previous ulceration or amputation we observed that all amputated patients remember the monitoring $(p<0.01)$.

We then asked to the patient if someone assisted them in the monitoring visit during lockdown: as reported in Fig. 2, 169 patients $(82.1 \%)$ were alone during the visit, 24 patients $(11.7 \%)$ performed it with their partner, for 10 patients (4.8\%) was present also a son or daughter and eventually 3 patients $(1.5 \%)$ made the visit with a grandson or another relative.

\section{Patients' satisfaction for telemedicine interaction}

As reported in Fig. 3, patients judged the telemedicine contact during pandemic useful, assigning a mean score of $4.35 \pm 0.28$ on a maximum of five. They considered useful also the indications given by the specialist regarding how to manage with foot care, obtaining a score of $4.11 \pm 0.22$ on a maximum of five. And eventually, when we asked the patients about their availability in continuing this contact modality, in parallel to traditional outpatient visits, also after end of lockdown, they demonstrated a very positive opinion, giving a score of $4.34 \pm 0.23$ on a maximum of five.

\section{Awareness and fear for COVID and for diabetic foot}

Eventually, also through a score ranging from 1, meaning not at all, to 5, meaning completely yes, we investigated awareness and fear of patients regarding both diabetic foot and COVID infection. In the whole cohort the fear of diabetic foot was significantly higher when compared to fear of COVID ( $4.79 \pm 0.05$ vs. $3.27 \pm 1.03, p<0.05)$. We went then to analyze the subset of patients with a history of ulceration or an active ulcer. In these patients, the fear for diabetic foot was even higher versus fear for COVID $(4.84 \pm 0.03$ vs.

Table 2 Characteristics of the patients who underwent to phone interview

\begin{tabular}{|c|c|c|c|c|c|c|c|c|c|c|}
\hline & \multirow[t]{2}{*}{ General } & \multicolumn{3}{|c|}{ Remember the call? } & \multicolumn{3}{|c|}{ Remember the person? } & \multicolumn{3}{|c|}{ Remember the reason? } \\
\hline & & Yes & No & $p$ & Yes & No & $p$ & Yes & No & $p$ \\
\hline Number of patients $(n / \%)$ & 206 & $177(85.9)$ & $29(14.1)$ & - & $140(67.9)$ & $66(32.1)$ & - & $181(87.9)$ & $25(12.1)$ & - \\
\hline Male $(n / \%)$ & $133(64.6)$ & 109 (61.6) & $21(72.4)$ & $<0.01$ & $87(62.1)$ & $43(65.1)$ & ns & $109(60.2)$ & $17(68.0)$ & $<0.01$ \\
\hline Mean age (years) & $72 \pm 10$ & $68 \pm 13$ & $73 \pm 11$ & $<0.01$ & $72 \pm 10$ & $71 \pm 11$ & ns & $71 \pm 12$ & $77 \pm 10$ & $<0.01$ \\
\hline Duration of diabetes (years) & $18 \pm 6$ & $18 \pm 7$ & $17 \pm 8$ & ns & $19 \pm 8$ & $17 \pm 9$ & ns & $18 \pm 5$ & $19 \pm 2$ & ns \\
\hline Previous ulceration (\%) & 82.5 & 82.8 & 17.2 & ns & 68.0 & 32.0 & ns & 87.6 & 12.4 & ns \\
\hline Previous amputation (\%) & 69.4 & 100 & 0 & $<0.01$ & 65.0 & 35.0 & ns & 85.3 & 14.7 & ns \\
\hline
\end{tabular}

Bold values represent the significative $p$ level 
90

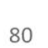

80

70

60

50

40

30

20

10
85.9

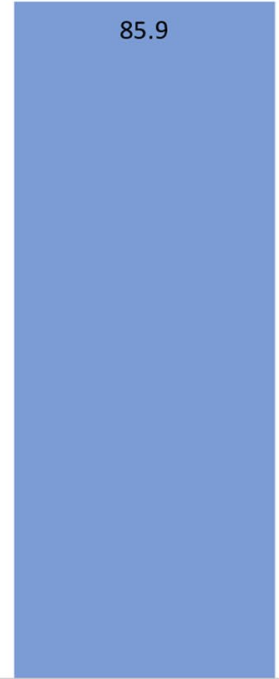

Remeber Contact

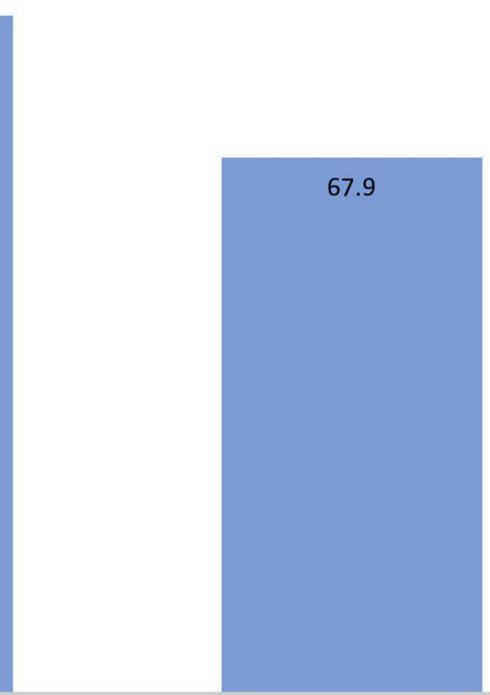

Remember Person
87.9

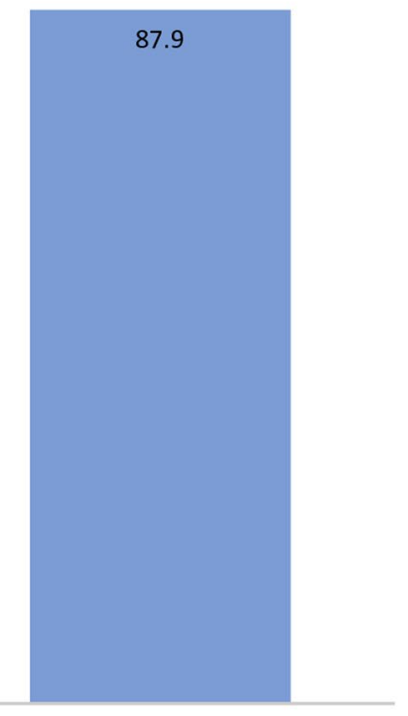

Remember Topic

Fig. 1 What patients remember about remote monitoring visit during lockdown

$\%$

1.5

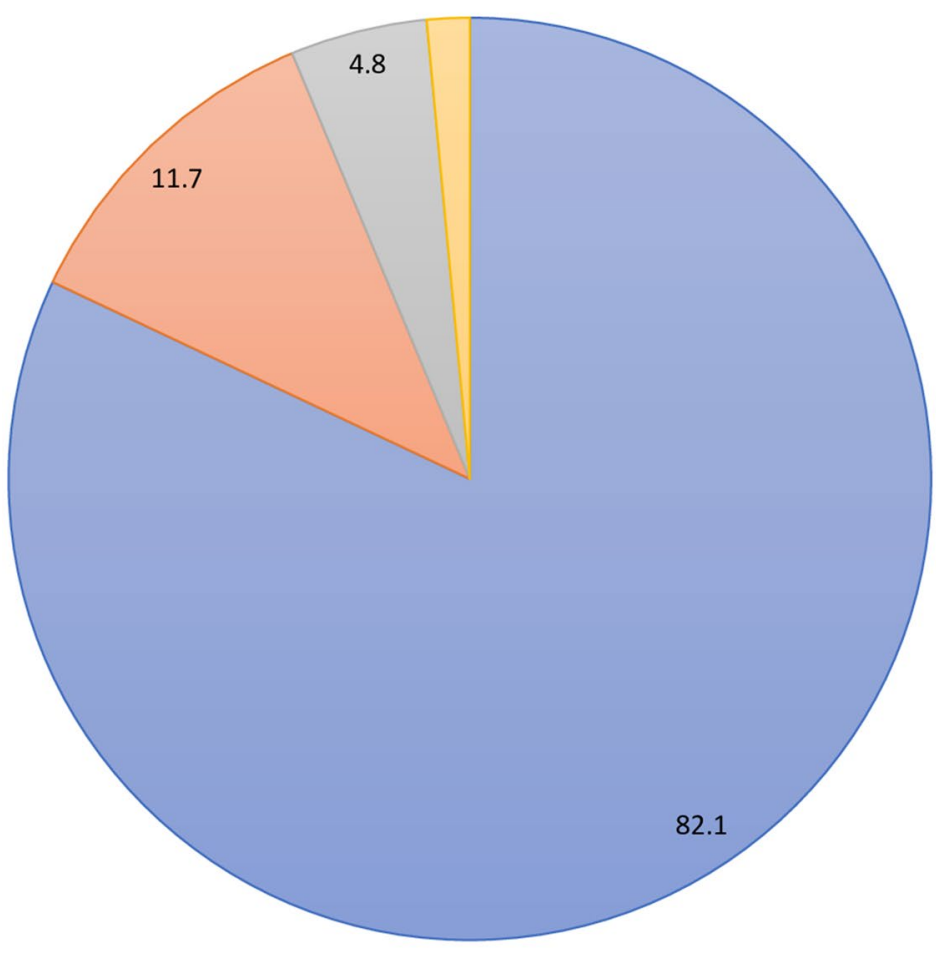

$\square$ Patient alone

$\square$ Partner

$\square$ Son/Daughter

$\square$ Other relative

Fig. 2 Participants at remote monitoring visit during lockdown 


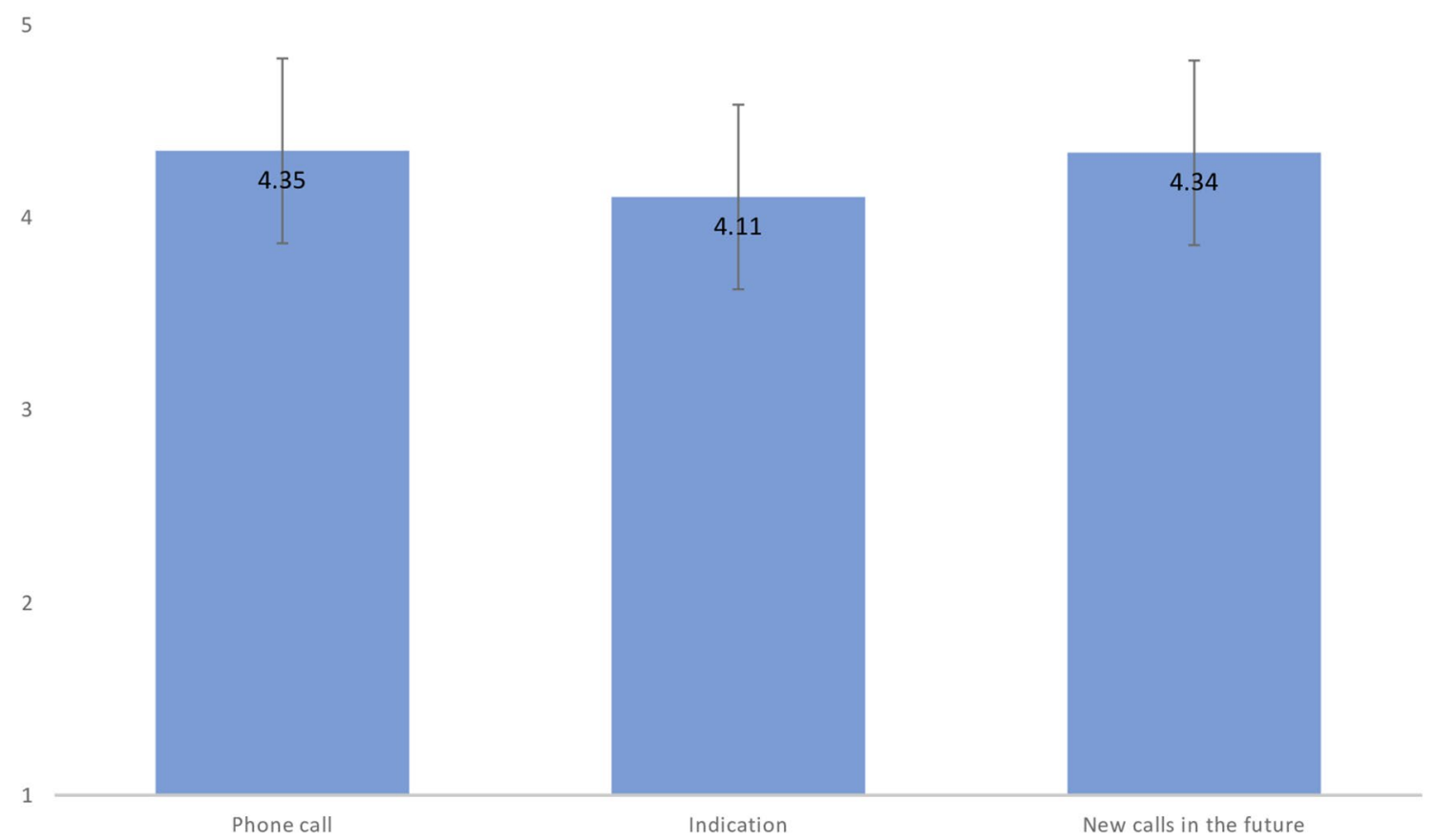

Fig. 3 Patients' satisfaction about remote monitoring visit during lockdown

$3.03 \pm 1.13, p<0.05)$. Eventually, the difference was even higher when comparing only values obtained by patients with a previous amputation $(4.93 \pm 0.03$ vs. $2.73 \pm 1.21$, $p<0.05)$. The differences in fear between the two diseases is 1.52 in the cohort as a whole and increases to 1.81 in previously ulcerated patients ( $p<0.02$ vs. general population) and to 2.20 in previously amputated patients ( $p<0.02$ vs. previous amputated patients and versus the whole cohort) (Fig. 4).

\section{Discussion}

Our study demonstrated how telemedicine can be well perceived by DF patients as a possible alternative to traditional visits and in the same time highlights how DF is more "heavy" than COVID in the patient's life.

DF syndrome is from many point of view a paradigmatic disease. From the beginning it is a typical multifactorial disease, where genetics and environment act together. From a clinical point of view, DF is, among the chronic complication of diabetes, the one where is needed the higher level of co-operation between the healthcare professionals and the patient [16].

COVID-19 pandemic interfered with this dynamic, leaving de facto many patients without care [17]. In this context, telemedicine was an alternative solution to continue to follow DF patients and in the same time to reduce their exposure to the risk of contagion [18].
Yet before COVID remote monitoring programs have been developed for patients with chronic wounds who could not reach hospital. The first steps of these programs were the activation of specialized home nurses to create the so called "Hospital at home" that allowed to deliver hospital-level care at home at these patients [19]. This strategy allowed to reduce hospital controls and readmissions to one fifth [20]. Teot et al. demonstrated that the remote monitoring approach, when well organized and associated with a correct patients' selection, could guarantee an outcome in terms of rate and time of healing at 6 months similar to that obtained with a traditional domiciliary nurse service [21]. The increasing development of such programs made it mandatory the test of patients' safety: Rasmussen demonstrated that teleconsulting was able to achieve levels of healing and to control the level of amputation similar to face-to-face visits, despite a moderate higher mortality [22].

Despite the use of telemedicine is widespread among different specialistic fields, with general good outcomes in terms of efficacy and efficiency, still little is known about the patient's perception and level of satisfaction on this modality [23-25].

Our experience put in evidence how among DF patients' telemedicine is well perceived and accepted. Patients were in favor of continuing televisits also as an ongoing modality in parallel with traditional visits, also after the end of lockdown, and this reinforce the acceptancy of this approach.

Eventually, a novel issue focused in our paper is the comparison between awareness of risk associated with DF 


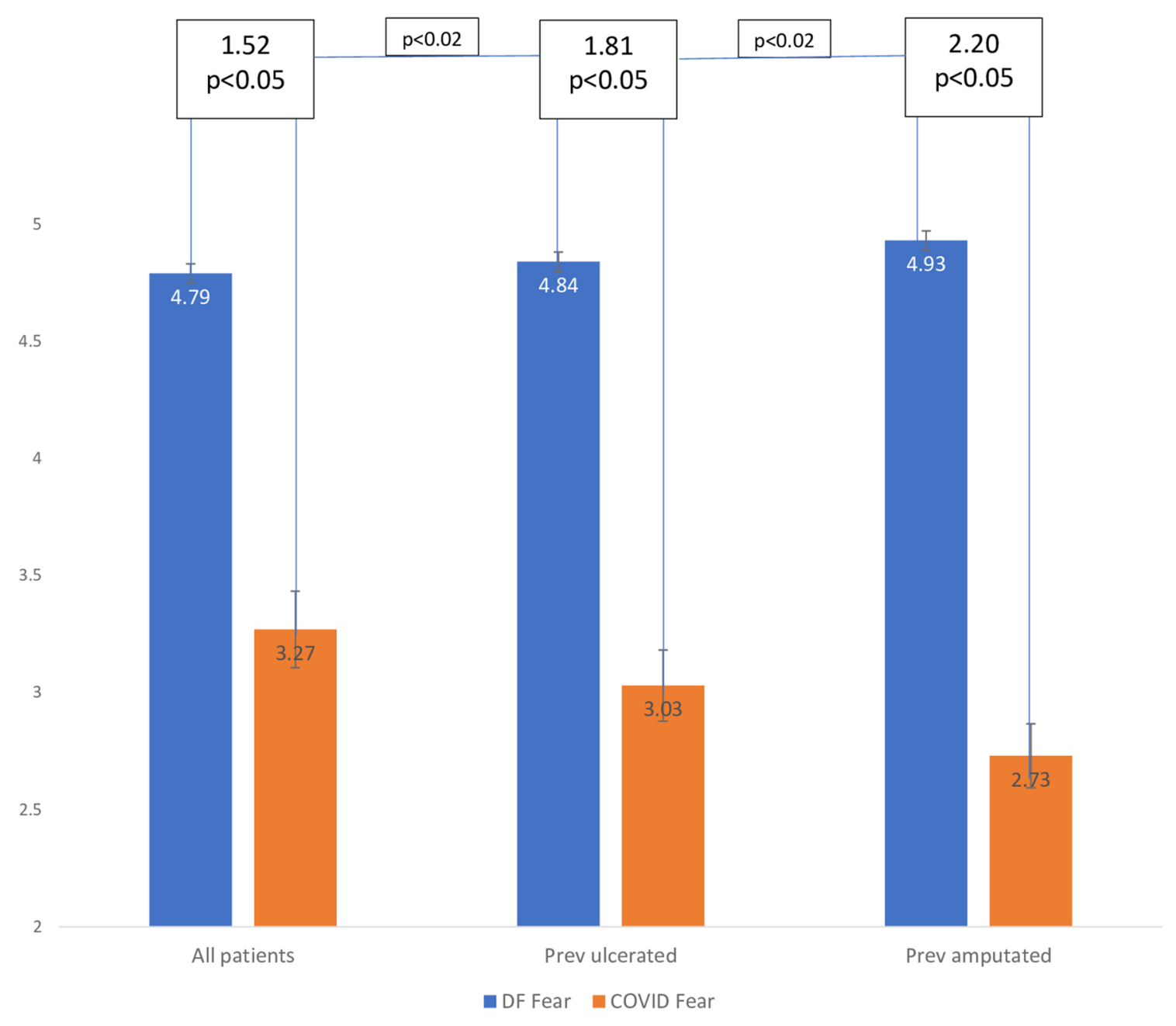

Fig. 4 Fear of COVID and fear of DF compared in different groups of general population

and to COVID infection in the patients' perception. When we analyzed our cohort as a whole the fear of patients for DF was significantly higher than the one for COVID. This discrepancy increased even further in previously ulcerated patients and in patients with an history of amputation.

In recent years, the study of psychological factors in patients with DF raised an increasing attention. Psychological patterns have been associated with changes in both patient's compliance and clinical outcome. Vileikyte and her coworkers recently associated the fear of patients for amputation to a better preventative foot self-care behavior [26].

Future perspective in this field are wide and significant: reducing the number of traditional visits in favor of remote monitoring is helpful not only in pandemic period but also after lockdown especially in patients frail, often bedridden, and in whom the simple transport to hospital can significantly decrease the quality of life. For this reason, as recommended by Tuscany health authority, we are implementing this program to maintain it active also after the end of COVID emergency and to normalize in our chronic patients this contact modality. We are aware of the limitations of this study, a retrospective survey on a limited number of patients from only one center, which hamper the generalizability of findings. Nevertheless, we find results worthwhile to be communicated, since they give information on an experience which is bound to be very common in the management of DF patients.

DF actually is not only a chronic disease, but a recurrent disease and as well-known after each new episode the severity of the disease increases progressively [27]. Therefore, enhancing the possibilities of contacts with these patients could allow us to implement a more efficient follow-up program. From this point of view telemedicine can be considered as a new tool for secondary prevention, to be integrated in the multidimensional therapeutic strategy for such a complex patient. 
Acknowledgements AP designed the study. EI, CG and LP performed the televisits. EI collected the data. AP and EI analyzed the data and wrote the manuscript. AP, EI, CG and LP revised the manuscript.

Funding No funding was obtained for the present study.

\section{Compliance with ethical standards}

Conflict of interest The authors declare that they have no conflict of interest.

Ethical standard All procedures performed in studies involving human participants were in accordance with the ethical standards of the institutional and/or national research committee and with the 1964 Helsinki Declaration and its later amendments or comparable ethical standards.

Informed consent Informed consent was obtained from all individual participants included in the study.

\section{References}

1. World Health Organization (2020) Pneumonia of unknown causeChina. https://www.who.int/csr/don/05-january-2020-pneumoniaof-unkown-cause-china/en/

2. World Health Organization (2020) Novel coronavirus - China. https ://www.who.int/csr/don/12-january-2020-novel-coronavirus-china/ en/

3. Huang C, Wang Y, Li X et al (2020) Clinical features of patients infected with 2019 novel coronavirus in Wuhan, China. Lancet 395(10223):497-506. https://doi.org/10.1016/S0140 -6736(20)30183-5 (published correction appears in Lancet, 30 Jan 2020)

4. Johns Hopkins University CSSE (2020) Wuhan coronavirus (2019$\mathrm{nCoV}$ ) global cases. https://gisanddata.maps.arcgis.com/apps/opsda shboard/index.html\#/bda7594740fd40299423467b48e9ecf6

5. Memish ZA, Ahmed QA, Schlagenhauf P, Doumbia S, Khan A (2020) No time for dilemma: mass gatherings must be suspended. Lancet 395(10231):1191-1192. https://doi.org/10.1016/S0140 $-6736(20) 30754-6$

6. Blumenthal D, Fowler EJ, Abrams M, Collins SR (2020) Covid19-implications for the health care system. N Engl J Med. https:// doi.org/10.1056/NEJMsb2021088 (published online ahead of print, 22 Jul 2020) (published correction appears in N Engl J Med, 23 Jul 2020)

7. Tran VT, Ravaud P (2020) COVID-19-related perceptions, context and attitudes of adults with chronic conditions: results from a cross-sectional survey nested in the ComPaRe e-cohort. PLoS ONE 15(8):e0237296. https://doi.org/10.1371/journal.pone.0237296

8. Jaly I, Iyengar K, Bahl S, Hughes T, Vaishya R (2020) Redefining diabetic foot disease management service during COVID-19 pandemic. Diabetes Metab Syndr 14(5):833-838. https://doi. org/10.1016/j.dsx.2020.06.023 (published online ahead of print, 11 Jun 2020)

9. Decreto del Presidente del Consiglio dei Ministri 9 marzo 2020. Gazzetta Ufficiale della Repubblica Italiana numero 62, anno 161

10. Allard R, Leclerc P, Tremblay C, Tannenbaum T-N (2010) Diabetes and the severity of pandemic Influenza A (H1N1) infection. Diabetes Care 33:1491. https://doi.org/10.2337/dc09-2215.LP-1493

11. Li B, Yang J, Zhao F et al (2020) Prevalence and impact of cardiovascular metabolic diseases on COVID-19 in China. Clin Res Cardiol 109:531-538. https://doi.org/10.1007/s00392-020-01626-9

12. Shin L, Bowling FL, Armstrong DG, Boulton AJM (2020) Saving the diabetic foot during the COVID-19 pandemic: a tale of two cities. Diabetes Care 43(8):1704-1709. https://doi.org/10.2337/ dc20-1176
13. Rogers LC, Lavery LA, Joseph WS, Armstrong DG (2020) All feet on deck-the role of podiatry during the COVID-19 pandemic: preventing hospitalizations in an overburdened healthcare system, reducing amputation and death in people with diabetes. J Am Podiatr Med Assoc. https://doi.org/10.7547/20-051 (published online ahead of print, 25 Mar 2020)

14. Delibera Regione Toscana n.464 del 4/6/2020 pubblicata su Bollettino Ufficiale Regione Toscana $n$

15. Najafi B (2020) Post the pandemic: how will COVID-19 transform diabetic foot disease management? J Diabetes Sci Technol 14(4):764-766

16. Piaggesi A, Apelqvist J (2018) The diabetic foot syndrome. Karger, Turin

17. Blanchette V, Brousseau-Foley M, Cloutier L (2020) Effect of contact with podiatry in a team approach context on diabetic foot ulcer and lower extremity amputation: systematic review and metaanalysis. J Foot Ankle Res 13(1):15. https://doi.org/10.1186/s1304 7-020-0380-8

18. Apicella M, Campopiano MC, Mantuano M, Mazoni L, Coppelli A, Del Prato S (2020) COVID-19 in people with diabetes: understanding the reasons for worse outcomes. Lancet Diabetes Endocrinol. https://doi.org/10.1016/S2213-8587(20)30238-2 (published online ahead of print, 17 Jul 2020)

19. Leff B, Burton L, Mader SL et al (2005) Hospital at home: feasibility and outcomes of a program to provide hospital-level care at home for acutely ill older patients. Ann Intern Med 143:798-808

20. Caplan GA, Sulaiman NS, Mangin DA, Aimonino Ricauda N, Wilson AD, Barclay L (2012) A meta-analysis of "hospital in the home." Med J Aust 197:512-519

21. Téot L, Geri C, Lano J, Cabrol M, Linet C, Mercier G (2020) Complex wound healing outcomes for outpatients receiving care via telemedicine, home health, or wound clinic: a randomized controlled trial. Int J Low Extrem Wounds 19(2):197-204. https://doi. org/10.1177/1534734619894485

22. Rasmussen BS, Froekjaer J, Bjerregaard MR et al (2015) A randomized controlled trial comparing telemedical and standard outpatient monitoring of diabetic foot ulcers. Diabetes Care 38(9):1723-1729

23. Kaur D, Galloway GK, Oyibo SO (2020) Patient satisfaction with the use of telemedicine in the management of hyperthyroidism. Cureus 12(8):e9859

24. Odeh R, Gharaibeh L, Daher A, Kussad S, Alassaf A (2020) Caring for a child with type 1 diabetes during COVID-19 lockdown in a developing country: challenges and parents' perspectives on the use of telemedicine. Diabetes Res Clin Pract. https://doi.org/10.1016/j. diabres.2020.108393 (published online ahead of print, 25 Aug 2020)

25. Zhu C, Williamson J, Lin A et al (2020) Implications for telemedicine for surgery patients after COVID-19: survey of patient and provider experiences. Am Surg. https://doi.org/10.1177/0003134820 945196 (published online ahead of print, 17 Aug 2020)

26. Vileikyte L, Pouwer F, Gonzalez JS (2020) Psychosocial research in the diabetic foot: are we making progress? Diabetes Metab Res Rev 36(Suppl 1):e3257

27. Armstrong DG, Boulton AJM, Bus SA (2017) Diabetic foot ulcers and their recurrence. N Engl J Med 376(24):2367-2375. https://doi. org/10.1056/NEJMra1615439

Publisher's Note Springer Nature remains neutral with regard to jurisdictional claims in published maps and institutional affiliations. 